\title{
Assessment of the redistribution of soil carbon using a new index - a case study in the Haihe River Basin, North China
}

\author{
Yuhe Ji • Liding Chen • Guangsheng Zhou • \\ Ranhao Sun • Linyuan Shang • Shudong Wang
}

Received: 27 March 2014 / Accepted: 25 July 2014 / Published online: 5 August 2014

(C) Springer International Publishing Switzerland 2014

\begin{abstract}
Soil carbon redistribution is an important process in the terrestrial carbon cycle. This study describes a new index, soil carbon redistribution (SCR) index, that can be used to assess long-term soil carbon redistribution at a large watershed scale. The new index is based on the theoretical preconditions that soil carbon redistribution is mainly controlled by vegetation type, precipitation, topography/slope, and soil carbon concentration. The Haihe River Basin served as an example for this analysis. The SCR index was calculated, and a GIS-based map shows its spatial patterns. The results suggested that soil carbon was usually prone to being carried away from mountainous regions with natural vegetation, while it was prone
\end{abstract}

Y. Ji • G. Zhou

Chinese Academy of Meteorological Science,

Beijing 100081, China

Y. Ji

e-mail: yuheji@163.com

G. Zhou

e-mail: gszhou@ibcas.ac.cn

Y. Ji

State Key Laboratory of Vegetation and Environmental

Change, Institute of Botany, Chinese Academy of Sciences,

Beijing 100093, China

L. Chen $(\bowtie) \cdot$ R. Sun

State Key Laboratory of Urban and Regional Ecology,

Research Center for Eco-environmental Sciences, Chinese

Academy of Sciences, Beijing 100085, China

e-mail: liding@rcees.ac.cn to deposition in the plain and plateau regions with cultivated vegetation. The methods in the paper offer a tool that can be used to quantify the potential risk where soil carbon is prone to being carried away and deposited in a large watershed.

Keywords Carbon cycle $\cdot$ Carbon loss $\cdot$ SCR index $\cdot$ Soil erosion $\cdot$ Vegetation $\cdot$ Slope

\section{Introduction}

Complex carbon exchange processes occur between soil, vegetation, and the atmosphere (e.g., photosynthesis, respiration, and decomposition).

R. Sun

e-mail: rhsun@rcees.ac.cn

\author{
L. Shang \\ Department of Earth, Atmospheric and Planetary Sciences, \\ Purdue University, 550 Stadium Mall Drive, West Lafayette, \\ IN 47907-2051, USA \\ e-mail: 1shang@purdue.edu
}

S. Wang

State Key Laboratory of Remote Sensing Science, Institute of

Remote Sensing and Digital Earth, Chinese Academy of

Science, Beijing 100101, China

e-mail: wangsd@irsa.ac.cn 
Soil carbon redistribution (also known as relocation or translocation) is a physical and ecological transportation process that is part of the global carbon cycle (Dawson \& Smith 2007; Zhang et al. 2013); it includes erosion, leaching, transfer and deposition, etc., which usually alter the location of soil carbon directly (Gregorich et al. 1998; Sanderman \& Amundson 2009; Shi et al. 2009).

Soil carbon redistribution is impelled primarily by surface erosion processes, which relate to many natural factors (Janzen 2004; Editorial 2005; Hirmas et al. 2010). Vegetation type was one of the natural factors controlling soil carbon redistribution (Sitaula et al. 2004), since vegetation can help soil retain its carbon based on its physical structures (Van Miegroet et al. 2005). Chen et al. (2011) discovered that forests prevented soil carbon from loss better than grass, and grass prevented soil carbon from loss better than bare land. The change of vegetation type usually changed soil carbon redistribution (Sitaula et al. 2004). Soil carbon usually tended to decrease after natural vegetation was converted into cropland vegetation types (Lal 2002; Shibu et al. 2010). Precipitation plays an important role in soil carbon redistribution. Abundant precipitation usually leads to very strong hydrologic erosion forces that transport dissolved and particulate carbon along hydrologic flow paths (McCarty \& Ritchie 2002; Davidson \& Janssens 2006). A laboratory simulation suggested that more carbon was carried away from surface soil layer when precipitation increased (Rimal \& Lal 2009; Stavi \& Lal 2011). Topographical factors were also related to soil carbon redistribution (Wang et al. 2010; Schwanghart \& Jarmer 2011). Soil carbon was usually prone to deposition (or sequestration) in low-lying areas but was lost from upper slopes (Fang et al. 2006). More soil carbon was prone to being lost on steeper slopes because of hydrological erosion (Page et al. 2004; Hancock et al. 2010). Doetterl et al. (2012) discovered that $75 \%$ of the variability of soil erosion could be explained by precipitation and slope, while soil characteristics contributed only a small amount (Doetterl et al. 2012). In addition, soil carbon itself is the source to supply carbon redistribution. More carbon tends to be lost from soils with a higher concentration of soil carbon, because more soil carbon is exposed to erosion (Cowie et al. 2006). In conclusion, soil carbon redistribution is controlled mainly by vegetation type, precipitation, topography/slope, and soil carbon concentration.

A variety of models have been developed to assess soil carbon redistribution. For example, the Global Environment Facility Soil Organic Carbon (GEFSOC) Modeling System was used to estimate soil organic carbon stocks and variations in that stock (Kamoni et al. 2007). Smith et al. (2007) used the Revised Universal Soil Loss Equation (RUSLE) to estimate the loss of soil organic carbon in a Mediterranean-climate watershed. Others have used geographic information system (GIS)based erosion models to identify carbon redistribution (Smith et al. 2007; Avtar et al. 2011). The Soil Water Assessment Tool (SWAT) has been used to simulate the transport processes of soil carbon; however, these models require a considerable number of ecophysiological and site parameters (Kemanian et al. 2011; Xu et al. 2011), and some parameters are rarely available.

The objective of this study was to develop a SCR index that could be used to quantify soil carbon redistribution by modeling vegetation type, precipitation, topography/slope, and soil carbon concentration. The Haihe River Basin served as an analysis area. GIS techniques were adopted to explore the spatial patterns of soil carbon redistribution. This study provides an assessment of whether a specific area will suffer from carbon loss or deposition over the long term as a result of natural forces.

\section{Materials and methods}

Study area

The study was conducted in the Haihe River Basin and covered a total area of $31.8 \times 10^{4} \mathrm{~km}^{2}$, in North China $\left(35^{\circ}-43^{\circ} \mathrm{N}, 112^{\circ}-120^{\circ}\right.$ E; Fig. 1). The Haihe River Basin is a rather large watershed (basin). The semi-humid and semi-arid temperate continental monsoon climate has an average annual precipitation of approximately $535 \mathrm{~mm}$ (Zheng and Li 2009). Plateaus (the Loess and Inner Mongolian plateaus), mountains (the Yanshan and Taihang mountains), and an alluvial plain (Haihe River 


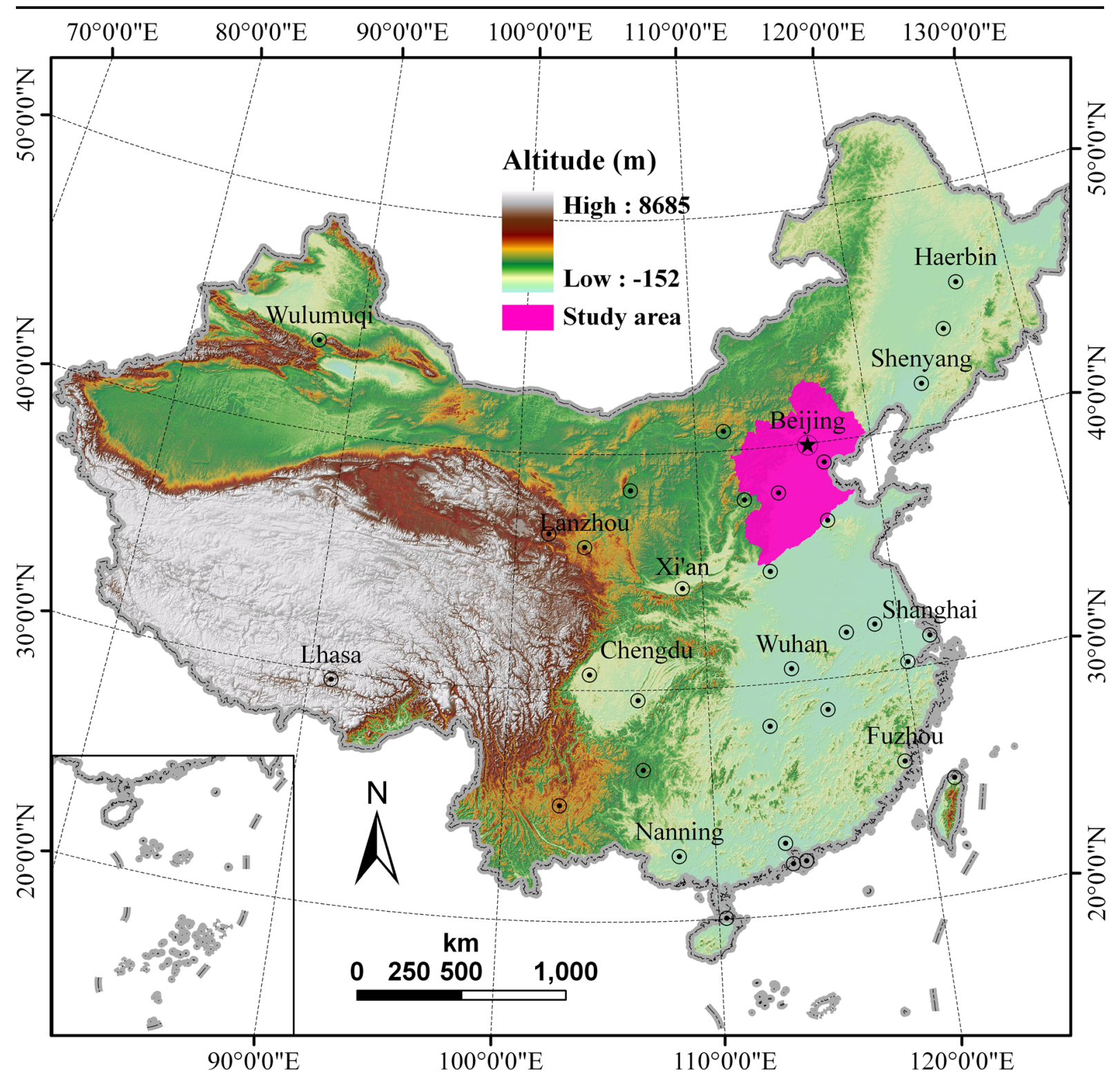

Fig. 1 Location of study area in the Haihe River Basin, China

Plain) contribute to the varied topography. In the mountains, natural shrubs as well as coniferous and deciduous forest form the dominant vegetation types. On the plateaus, the dominant vegetation types are natural meadow and cultivated crops. The plains also support cultivated crops.

\section{SCR index}

In this study, a soil carbon redistribution (SCR) index was developed to quantify the long-term soil carbon redistribution in the Haihe River Basin. The theoretical rationale for SCR index can be summarized as follows: soil carbon itself is the source to supply carbon redistribution, vegetation contributes to preventing soil carbon loss, precipitation contributes to promoting soil carbon loss, and topographical factor contributes to soil carbon loss or deposition. Therefore, the index relied on theoretical preconditions: soil carbon redistribution is controlled mainly by vegetation type, topography/slope, annual precipitation, and soil carbon 
concentration, which have been proved reliable by previous studies (Sitaula et al. 2004; Cowie et al. 2006; Rimal \& Lal 2009; Hancock et al. 2010; Schwanghart \& Jarmer 2011; Stavi \& Lal 2011). However, the index focused on a long-term potential trend of soil carbon distribution, not only a single loss process from a single rainfall event.

Calculating the SCR index required data related to four environmental variables from four maps: a digital vegetation-type map, gridded topography/slope, gridded annual precipitation, and digital soil carbon concentration maps.

The digital vegetation map was derived from Landsat TM images captured in the year 2000 (Fig. 2). The vegetation map included 16 vegetation types and approximately 2,800 polygons with classified vegetation types, which follows the classification system of Chinese vegetation map. Each polygon in the vegetation map not only has its vegetation type and area but also acts as a basic spatial unit to assess soil carbon redistribution.

The gridded topography/slope map was derived from the grid-based digital elevation model (DEM) data (Fig. 3). Slope value was calculated from a $3 \times 3$ cell neighborhood in DEM by using the surface analysis module in the spatial analyst extension from ArcGIS 10 software; next, a gridded slope map was created over the study area.

A gridded precipitation map was derived from annual mean data from 40 weather stations during the period 1960-2000 (Fig. 4). The weather stations only offered some isolated point-based precipitation data. The isolated point precipitation data were interpolated into a gridded map over the study area by the ordinary Kriging method of ArcGIS 10.

A digital soil carbon concentration map was derived from the digital vegetation map and a soil carbon survey based on vegetation types (Fig. 5). The initial soil carbon concentration for each vegetation type was obtained from soil samples at 370 sites in the study area collected during 2009-2010 (Fig. 6). The number of soil sampling sites was set according to the area of vegetation type, so there were much more soil sampling sites where vegetation type covers a larger area. Soil samples were collected from depths of 0 to $10 \mathrm{~cm}$ at each sampling site. In the laboratory, soil samples were air-dried, passed through a 2-mm-mesh sieve, and analyzed for total soil carbon concentration using a Vario EL III elemental analyzer (Elementar, Hanau, Germany). The soil carbon concentration for each vegetation type was obtained from the mean value of 14-43 soil samples, depending on the total spatial extent of each soil type. The soil carbon concentration for each polygon in the digital vegetation map was assigned a value of soil carbon concentration based on its vegetation type and then a soil carbon concentration map was produced.

Each polygon in the digital vegetation map acted as a basic spatial unit and was used to calculate its mean slope and mean annual precipitation using the zonal statistics tool of ArcGIS 10 software. Each spatial unit (namely, polygon in digital vegetation map) was assigned a mean slope, which was the average slope from the gridded cells in each respective same spatial unit (polygon). In the same way, each spatial unit was assigned a mean annual precipitation. Ultimately, each spatial unit in the map was assigned four characteristics: a vegetation type (polygon of vegetation type as spatial unit) and a mean slope, annual precipitation, and soil carbon concentration.

Based on each spatial unit (namely, polygon) in the digital vegetation map, a new SCR index was developed. The SCR index $r$ for each spatial unit (polygon) was calculated using Formula (1), which considered the four characteristics listed in the above paragraph.

$r=\frac{1}{3} \sum_{k=i}^{3} z_{i}, z_{i}=\frac{x_{i}-\bar{x}_{i}}{\sigma}$

where $r$ is the SCR index; $i$ is one of the three factors (topography/slope, annual precipitation, or soil carbon concentration); $z_{i}$ is a standardized variable of each factor from the three factors in each spatial unit (vegetation polygon), and $z_{i}$ represents the distance between a initial data point in each spatial unit (vegetation polygon) and its mean for each factor in the whole research area; $x_{i}$ is a initial data point in each spatial unit (vegetation polygon); $\bar{x}_{i}$ is the mean for each factor from the three factors 


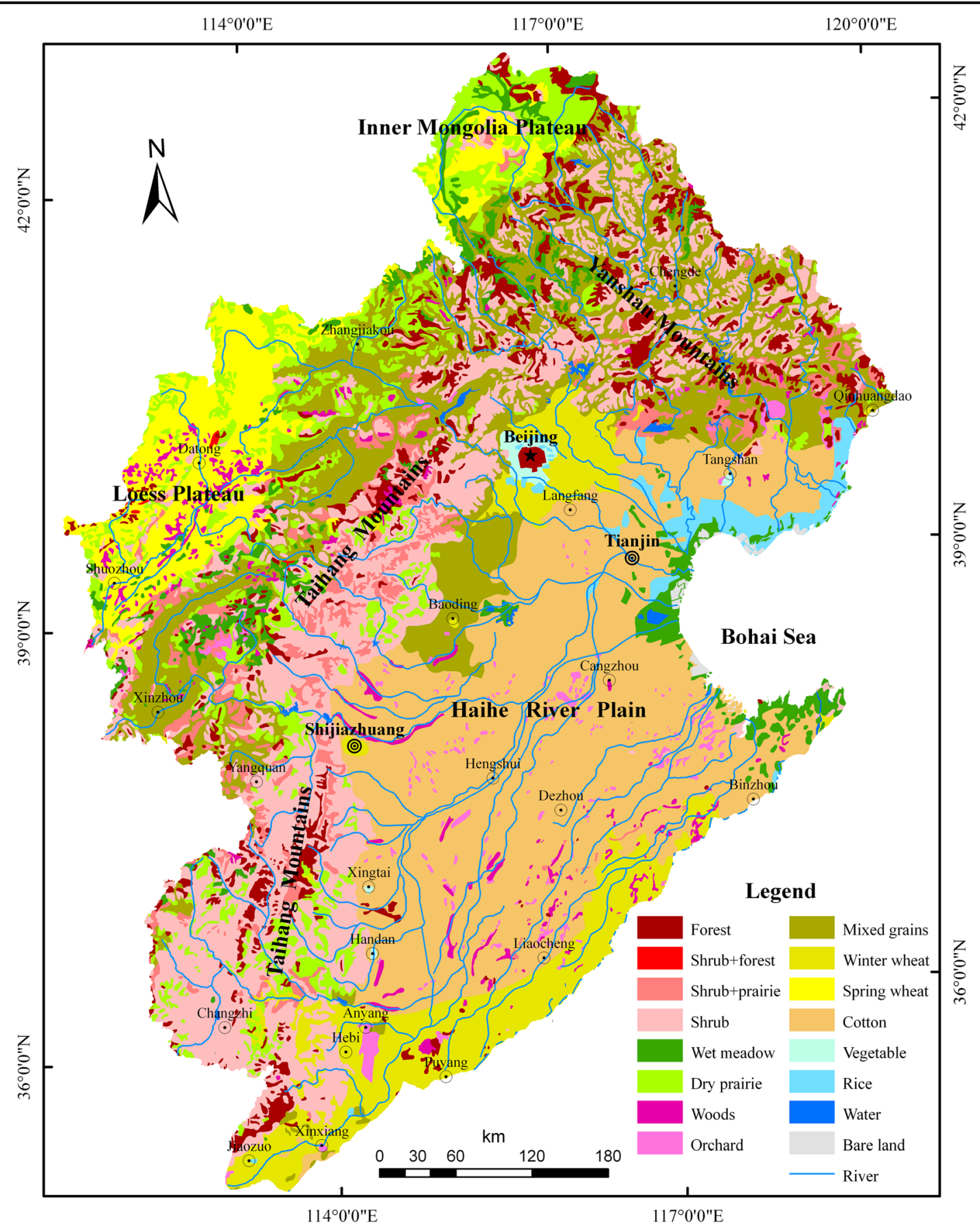

Fig. 2 Digital vegetation map of the Haihe River Basin, China

in the whole research area; and $\sigma$ is the standard deviation in the whole research area.

The index $r$ allowed us to identify the intensity and trend of soil carbon redistribution, where $r=0$ denotes an averaged intensity of soil carbon redistribution, and a positive $(r>0)$ or negative $(r<0)$ index value denotes that the soil carbon tends to be eroded or deposited in the polygon, respectively. Thus, the spatial units (the polygons in the digital vegetation map) with a positive or negative index value $(r>0$ or $r<0)$ can be identified as 


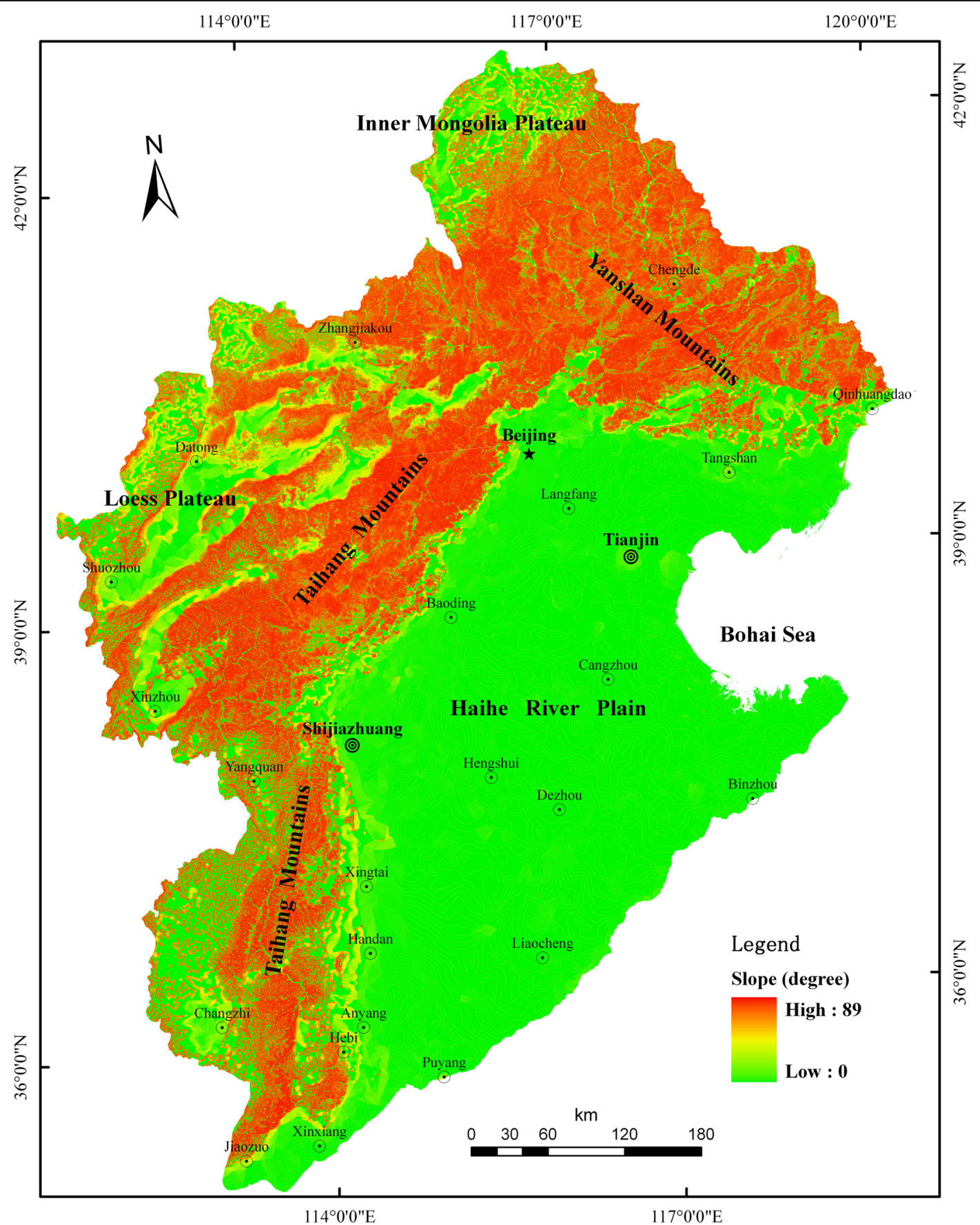

Fig. 3 Topographical and slope map of the Haihe River Basin, China

outflow or inflow regions where soil carbon is carried away or deposited, respectively. The absolute value of $r$ indicates the intensity of soil carbon redistribution with larger or more negative values indicating a stronger intensity of positive or negative soil carbon redistribution, respectively. A map was prepared based on $r$ in the polygons in the digital vegetation map to allow us to visually determine where soil carbon will be carried away or deposited at any particular location. 


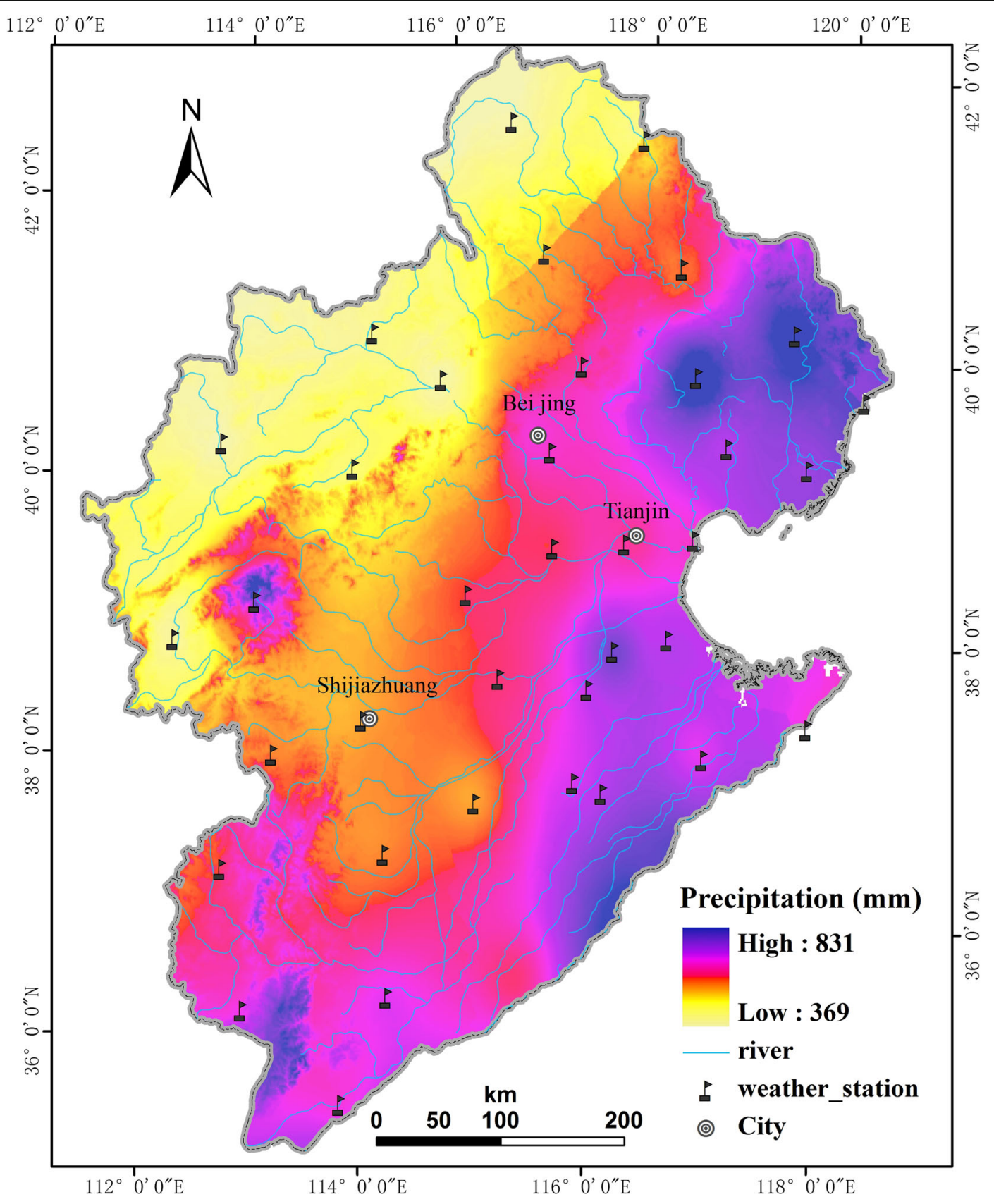

Fig. 4 Map of annual precipitation for 1960-2000 in the Haihe River Basin, China

\section{Results}

Identifying the inflow regions for soil carbon redistribution

The SCR index $r$ measures the inflow or outflow trends of soil carbon, as discussed above. Various geomorphic zones, such as the eastern plain (Haihe
River Plain) as well as western plateaus (Inner Mongolia Plateau and Loess Plateau), were identified as inflow regions where higher-intensity soil carbon inflow occurred; this was especially true in the transition zone between the mountains and plains (Figs. 3 and 7).

Almost all cultivated vegetation zones showed a negative index value $(r<0)$, which denoted an inflow of soil 


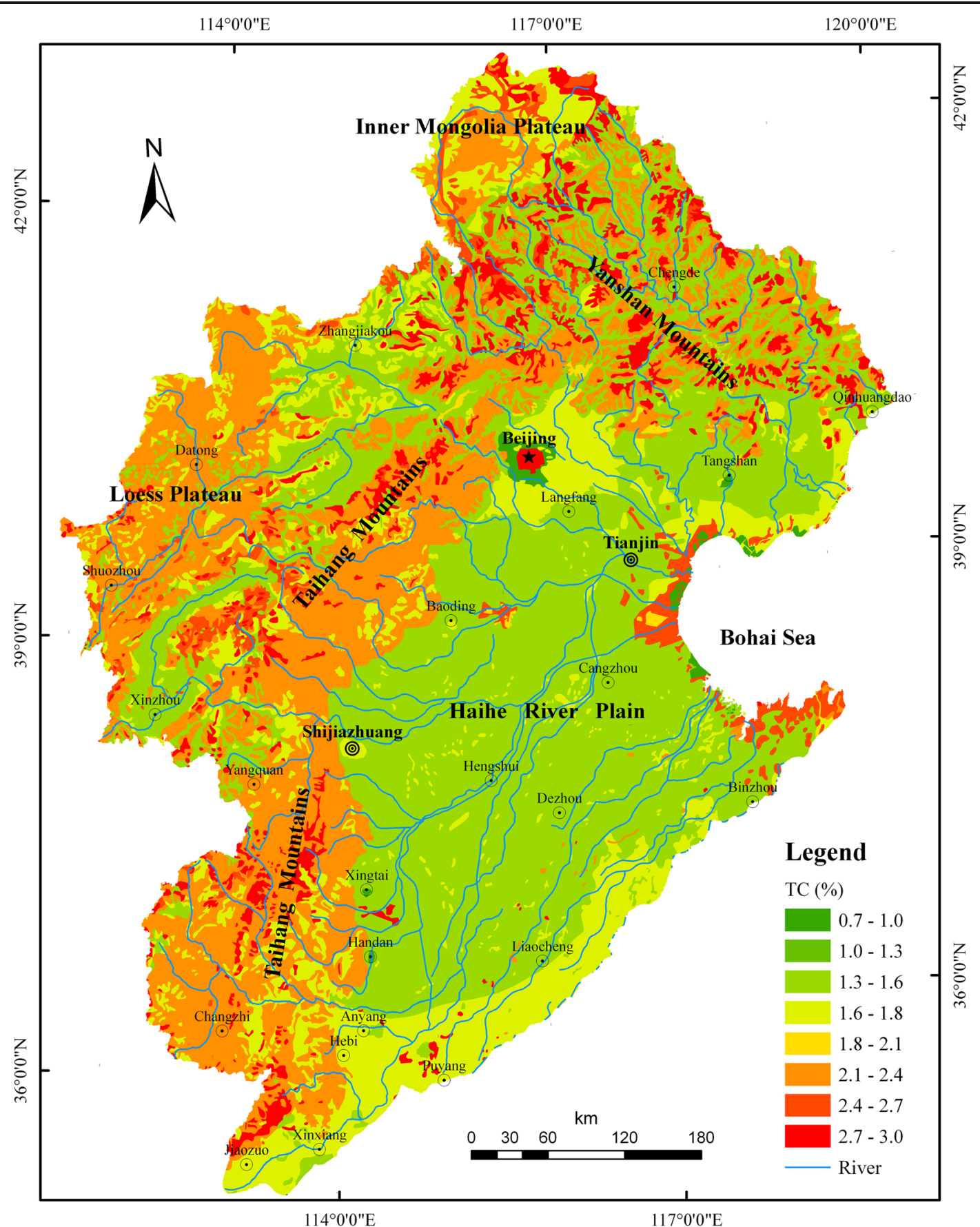

Fig. 5 Map of soil carbon concentration for the Haihe River Basin, China

carbon. The strongest inflows of soil carbon were seen in bare land and cultivated vegetation zones with average soil carbon redistribution indices of -0.994 and -0.913 , respectively. The inflow trends in cultivated vegetation zones often occurred with a relatively smaller slope gradient and smaller carbon concentration (Table 1). The relatively smaller slope contributes to receiving carbon from natural vegetation zones which often lie at a higher place with rich soil carbon. The smaller carbon concentration lets small amounts of carbon loss. 


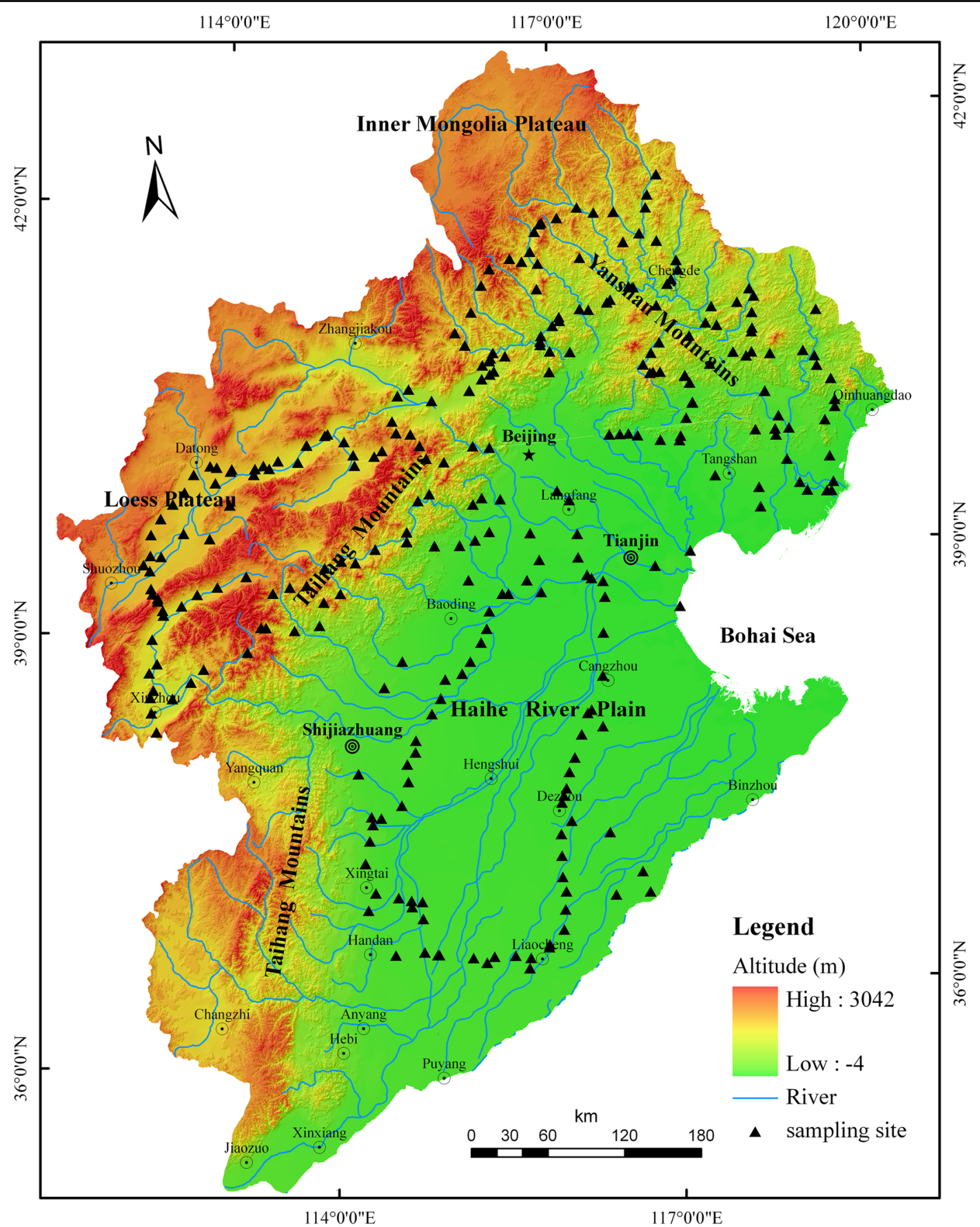

Fig. 6 Sampling sites of soil carbon surveys in the Haihe River Basin, China

Polygons with smooth topography were prone to receive an input of soil carbon, although this higher inflow had different causes for eastern plains and western plateaus. In eastern plains, the higher inflow intensity was mainly caused by smooth topography and poor carbon in soil (plains, Figs. 3 and 5). In western plateaus, the higher inflow intensity was mainly caused by smooth topography and poor precipitation since poor precipitation stops hydrologic erosion carrying soil carbon away (plateaus, Figs. 3 and 4). 


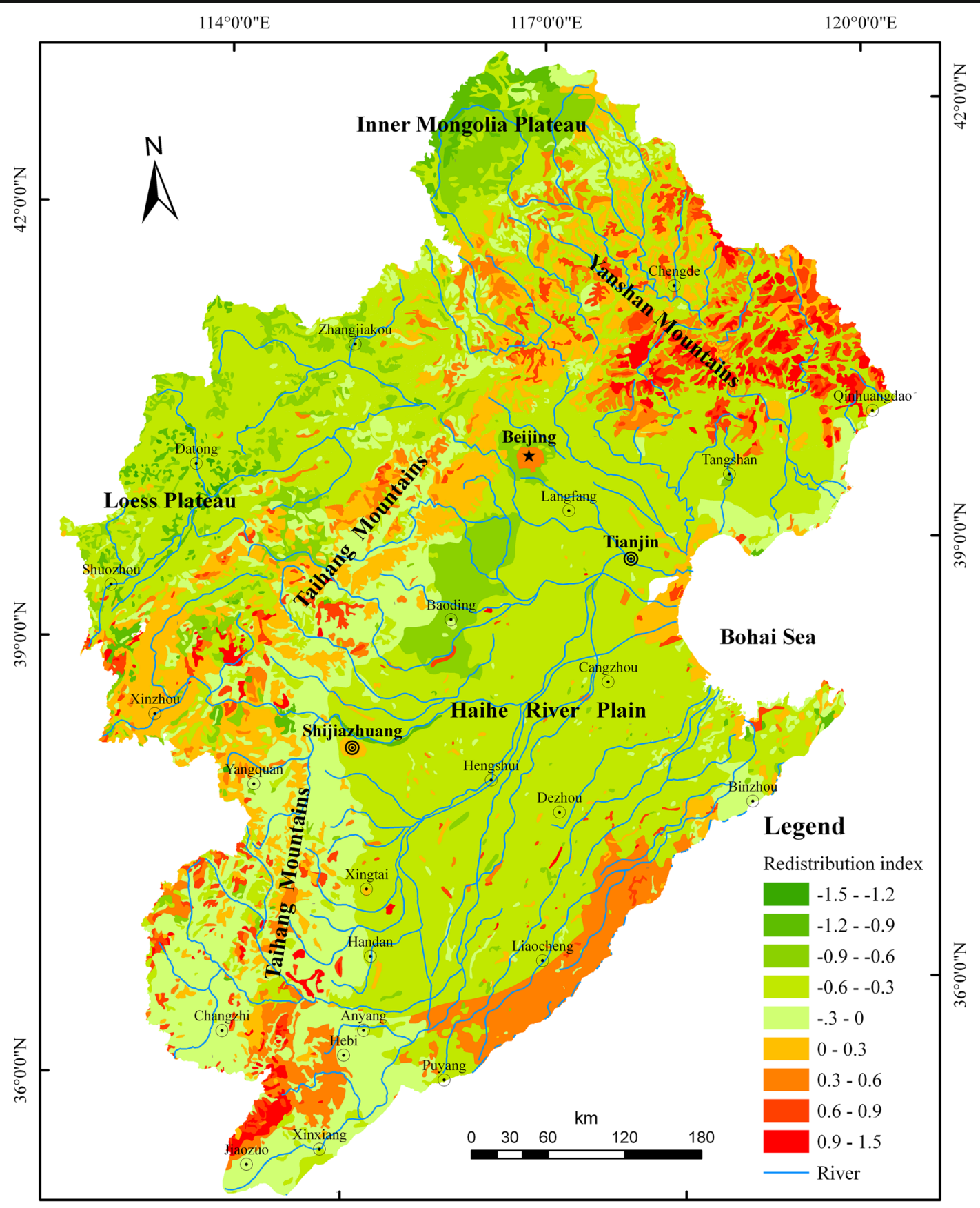

$114^{\circ} 0^{\prime} 0 " \mathrm{E}$

$117^{\circ} 0^{\prime} 0 " \mathrm{E}$

Fig. 7 Spatial patterns of soil carbon redistribution in the Haihe River Basin, China

Identifying the outflow region for soil carbon redistribution

A larger positive index value $(r>0)$ identified outflow regions with a higher outflow intensity of soil carbon. Higher outflow intensity of soil carbon mainly occurred in the Yanshan and Taihang mountains. The highest outflow intensity was seen in the Yanshan Mountains where steeper slopes and abundant precipitation offer powerful hydrologic forces, and where the carbon concentration supply was rich enough to support carbon outflow during erosion. Generally, the combination of 
Table 1 SCR index in different vegetation types in the Haihe River Basin

\begin{tabular}{|c|c|c|c|c|c|c|}
\hline $\begin{array}{l}\text { Vegetation } \\
\text { attribute }\end{array}$ & Vegetation type & $\begin{array}{l}\text { Total area } \\
\left(\mathrm{km}^{2}\right)\end{array}$ & $\begin{array}{l}\text { Total soil } \\
\text { carbon } \\
\pm \text { S.D. (\%) }\end{array}$ & $\begin{array}{l}\text { Annual } \\
\text { precipitation } \\
\pm \text { S.D. }(\mathrm{mm})\end{array}$ & $\begin{array}{l}\text { Slope } \\
\text { gradient } \\
\pm \text { S.D. }\end{array}$ & $\begin{array}{l}\text { Index } \\
\pm \text { S.D. }\end{array}$ \\
\hline Natural & Forest & 17,865 & $3.0 \pm 2.2$ & $568 \pm 86$ & $64 \pm 22$ & $0.728 \pm 0.359$ \\
\hline Natural & Shrub & 58,791 & $2.2 \pm 1.4$ & $538 \pm 79$ & $66 \pm 17$ & $0.108 \pm 0.330$ \\
\hline Natural & Shrub + prairie & 11,988 & $2.2 \pm 1.0$ & $557 \pm 79$ & $53 \pm 23$ & $0.105 \pm 0.297$ \\
\hline Natural & Wet meadow & 10,984 & $2.4 \pm 1.3$ & $538 \pm 82$ & $31 \pm 33$ & $0.046 \pm 0.305$ \\
\hline Natural & River + lake & 1,058 & $1.9 \pm 1.0$ & $586 \pm 78$ & $17 \pm 23$ & $-0.222 \pm 0.344$ \\
\hline Cultivated & Winter wheat rotated maize & 24,256 & $1.8 \pm 0.5$ & $594 \pm 43$ & $19 \pm 23$ & $-0.299 \pm 0.377$ \\
\hline Cultivated & Spring wheat & 19,861 & $2.1 \pm 1.2$ & $464 \pm 64$ & $47 \pm 25$ & $-0.313 \pm 0.371$ \\
\hline Natural & Shrub + forest & 146 & $2.2 \pm 1.2$ & $451 \pm 32$ & $47 \pm 29$ & $-0.327 \pm 0.244$ \\
\hline Cultivated & Orchard & 3,423 & $1.7 \pm 0.9$ & $598 \pm 57$ & $6 \pm 17$ & $-0.362 \pm 0.254$ \\
\hline Cultivated & Mixed grains & 52,275 & $1.4 \pm 0.7$ & $576 \pm 63$ & $40 \pm 28$ & $-0.395 \pm 0.289$ \\
\hline Cultivated & Rice & 4,449 & $1.6 \pm 0.0$ & $605 \pm 24$ & $3 \pm 6$ & $-0.404 \pm 0.099$ \\
\hline Natural & Dry prairie & 23,355 & $1.7 \pm 0.7$ & $492 \pm 81$ & $51 \pm 21$ & $-0.440 \pm 0.353$ \\
\hline Cultivated & Cotton & 83,070 & $1.6 \pm 0.2$ & $602 \pm 36$ & $2 \pm 1$ & $-0.480 \pm 0.119$ \\
\hline Cultivated & Woods & 5,086 & $1.4 \pm 0.8$ & $530 \pm 101$ & $27 \pm 30$ & $-0.656 \pm 0.377$ \\
\hline Cultivated & Vegetable & 903 & $0.9 \pm 0.4$ & $580 \pm 50$ & $9 \pm 2$ & $-0.913 \pm 0.170$ \\
\hline Natural & Bare land & 613 & $0.7 \pm 0.0$ & $609 \pm 48$ & $1 \pm 1$ & $-0.994 \pm 0.182$ \\
\hline- & Average & - & $2.07 \pm 0.6$ & $545 \pm 86$ & $48 \pm 30$ & $0 \pm 0.567$ \\
\hline
\end{tabular}

rich soil carbon concentration, steep slope, and abundant annual precipitation contributed to the highest outflow intensity (Figs. 3, 4, 5, and 7).

Positive index values $(r>0)$ were observed in most natural vegetation zones (such as forest, shrub, shrubprairie, and wet meadow) where soil carbon redistribution showed an outflow trend. The strongest outflow intensity occurred in the natural forest zones, with an average SCR index of 0.728 . The outflow trends in most natural vegetation zones are often consistent with a higher carbon concentration and larger slope (Table 1). Thus, the higher carbon concentration supplies enough carbon for the outflows, and the larger slope makes the carbon easy to transport under the influence of gravity.

Identifying the key factors controlling the spatial patterns of soil carbon redistribution

Two criteria are needed to identity the key factors controlling the spatial patterns of soil carbon distribution: the factors must have an effect on soil carbon redistribution, and the spatial patterns of the factors must be similar to that of soil carbon redistribution. Determining which of the four environmental factors (vegetation type, topography/slope, annual precipitation, and soil carbon concentration) is more important than others proved to be very difficult. This is because all four factors exert important effects on soil carbon redistribution in different ways according to previous studies (Sitaula et al. 2004; Rimal \& Lal 2009; Hancock et al. 2010; Schwanghart \& Jarmer 2011; Stavi \& Lal 2011). Nevertheless, another method can be used to identify key factors. This can be done by comparing their spatial patterns with that of soil carbon redistribution.

The spatial patterns were found to be remarkably consistent between topography/slope and soil carbon redistribution across the Haihe River Basin, since the higher outflow of soil carbon usually occurred in rugged topography (mountains) with greater slopes, and the higher inflow usually occurred in smooth topography (plains and plateaus) with flatter topography (Figs. 3 and 7). In addition, fairly consistent spatial patterns were also observed between vegetation type and soil carbon redistribution, since the higher outflow and inflow intensities of soil carbon usually occurred in natural and cultivated vegetation zones, respectively (Table 1 and Fig. 7). However, some spatial inconsistencies between annual precipitation and soil carbon redistribution were 
discovered. For example, abundant annual precipitation falls in the eastern part of the analysis area; this should lead to a higher outflow intensity of soil carbon in this region if annual precipitation was a key factor controlling soil carbon redistribution. Nevertheless, a higher inflow intensity region for soil carbon was observed in the eastern part of the study region (Figs. 4 and 7). Some spatial inconsistencies were also seen between soil carbon concentration and soil carbon redistribution. For example, soil carbon concentration was much larger in the western parts of the study area and should lead to a higher outflow intensity of soil carbon in the region if the soil carbon concentration was a key factor controlling soil carbon redistribution. Nevertheless, a higher inflow intensity of soil carbon was found (Figs. 5 and 7).

As a result, vegetation type and topography/slope were identified as key factors controlling the spatial patterns of soil carbon redistribution. However, this does not mean this conclusion also applies in other regions, since natural factors vary spatially. For example, if one assumes the plains are homogeneous because they have the same topography/slope, and this same slope exerts the same influence on soil carbon redistribution everywhere, then the topography/slope could not be a key factor controlling the spatial patterns of soil carbon redistribution. Most likely, some other factors are the key factors controlling the spatial patterns of soil carbon redistribution because environmental factors vary spatially in different regions.

\section{Discussion}

The theoretical rationale for the reliability of the SCR index

Validating the reliability of the SCR index proved difficult based on observed data from the sites analyzed here, since this index is a synthetic index based on four physical environmental variables. However, the reliability of the SCR index could be validated by its theoretical rationale and key factors affecting its spatial patterns.

The SCR index is based on the theoretical rationale that vegetation type, topography/slope, precipitation, and soil carbon concentration are the most important natural physical forces controlling soil carbon redistribution. (1) The physical structure of vegetation may help retain carbon in the soil, and different vegetation types may exert different effects on soil carbon redistribution (Sitaula et al.
2004; Van Miegroet et al. 2005). (2) Topography/slope is an important driver of soil carbon redistribution. Soil loses more carbon in areas with steeper slopes (Page et al. 2004; Hancock et al. 2010). (3) Precipitation is also an important driver for soil carbon redistribution, since abundant precipitation can lead to significant hydrological erosion and a loss of soil carbon (Rimal \& Lal 2009; Stavi \& Lal 2011; Zhang et al. 2013). (4) The initial soil carbon concentration is the available source of carbon that provides a supply of carbon for redistribution. Areas rich in soil carbon are prone to losing greater amounts of carbon to erosion than areas with low soil carbon concentration (Cowie et al. 2006). Fortunately, the theoretical rationale has been proven reliable by many previous studies (Rimal \& Lal 2009; Hancock et al. 2010; Stavi \& Lal 2011; Zhang et al. 2013).

The key factors controlling the spatial patterns of soil carbon redistribution (SCR)

To identify the key factors controlling the spatial patterns of soil carbon redistribution, two criteria are necessary: the factors should not only have an effect on soil carbon dynamics but should also have a nonhomogeneous distribution spatially. For the SCR index used in this paper, four physical variables were assumed to exert effects on soil carbon redistribution. Initially, it was assumed they have the same effects before we identified key factors. Ultimately, vegetation type and topography/slope were identified as the main factors controlling the spatial patterns of soil carbon redistribution. Current knowledge of the soil carbon cycle agrees with this conclusion (Hancock et al. 2010; Wang et al. 2012; Gao et al. 2013). However, The SCR index paid more attention to natural factors rather than anthropogenic interruption, so it was not well known how much effects were coming from the anthropogenic factor. In fact, it was reported that anthropogenic interruption such as unfriendly and wrong ways to agriculture usually led to a huge loss of soil carbon (Wang et al. 2013).

The suitable scope and characteristics of the SCR index

Although anthropogenic interference also affects soil carbon redistribution, the SCR index does not assess the effects of human interference on soil carbon dynamics. The SCR index only quantifies a purely physical transport process in the ecosystem and does not include chemical and biological processes. The index focused on 
a long-term potential trend of soil carbon distribution. Therefore, it was especially suitable to assess a long-term potential trend of soil carbon distribution controlled by natural physical factors at the catchment scale.

The SCR index in this paper differed from the soil erosion models used by others. Most soil erosion models treated soil characteristics as important factors, but ignored soil carbon concentration (Alewell et al. 2008; Ozcan et al. 2008; Conforti et al. 2011). The soil carbon concentration was found to be a very important driving factor for the SCR index, since the initial soil carbon concentration is the source used to supply carbon for redistribution; the amount of soil carbon exposed to erosion certainly affects soil carbon redistribution.

\section{Conclusions}

The SCR index presented here offers a quantitative tool that can be used to assess a long-term soil carbon distribution controlled by natural physical factors at a rather large watershed scale. This index could allow us to measure the intensity and trend (inflow or outflow) of soil carbon redistribution in a way that is easily mapped. This makes it easy to identify sites where soil carbon is prone to being either carried away or deposited, and contributes to identifying the main factors controlling the spatial patterns of soil carbon distribution. However, this index only quantified a purely physical transport process and failed to account for anthropogenic effects on the redistribution of soil carbon; therefore, the index is not suitable for assessing soil carbon dynamics based on human interference.

Acknowledgments This study was jointly funded by The Division of Hydrological-ecological Function Zone in the Haihe River Basin project (2012ZX07501002002) and a project known as Climate Change: Carbon Budget and Related Issues of the Chinese Academy of Sciences (XDA0505020401, XDA05050408).

\section{References}

Alewell, C., Meusburger, K., Brodbeck, M., \& Baninger, D. (2008). Methods to describe and predict soil erosion in mountain regions. Landscape and Urban Planning, 88, 46-53.

Avtar, R., Singh, C. K., Shashtri, S., \& Mukherjee, S. (2011). Identification of erosional and inundation hazard zones in Ken-Betwa river linking area, India, using remote sensing and GIS. Environmental Monitoring and Assessment, 182, 341-360.

Chen, L., Li, Z. B., Li, P., Yu, G. Q., \& Jia, L. L. (2011). The coupling effect on soil erosion and nutrient lost under a simulated rainfall. Journal of Basic Science and Engineering, 19(Supplement), 170-177.

Conforti, M., Aucelli, P. P. C., Robustelli, G., \& Scarciglia, F. (2011). Geomorphology and GIS analysis for mapping gully erosion susceptibility in the Turbolo stream catchment (Northern Calabria, Italy). Natural Hazards, 56, 881-898.

Cowie, A., Smith, P., \& Johnson, D. (2006). Does soil carbon loss in biomass production systems negate the greenhouse benefits of bioenergy? Mitigation and Adaptation Strategies for Global Change, 11, 979-1002.

Davidson, E. A., \& Janssens, I. A. (2006). Temperature sensitivity of soil carbon decomposition and feedbacks to climate change. Nature, 440, 165-173.

Dawson, J. C., \& Smith, P. (2007). Carbon losses from soil and its consequences for land-use management. Science of the Total Environment, 382, 165-190.

Doetterl, S., Van Oost, K., \& Six, J. (2012). Towards constraining the magnitude of global agricultural sediment and soil organic carbon fluxes. Earth Surface Processes and Landforms, $37,642-655$.

Editorial. (2005). Soil erosion and carbon dynamics. Soil \& Tillage Research, 81, 137-142.

Fang, H. J., Cheng, S. L., Zhang, X. P., Liang, A. Z., Yang, X. M., \& Drury, S. M. (2006). Impact of soil redistribution in a sloping landscape on carbon sequestration in Northeast China. Land Degradation \& Development, 17, 89-96.

Gao, P., Wang, B., Geng, G. P., \& Zhang, G. C. (2013). Spatial distribution of soil organic carbon and total nitrogen based on GIS and geostatistics in a small watershed in a hilly area of Northern China. PLoS ONE, 8, 1-9.

Gregorich, E. G., Greer, K. J., Anderson, D. W., \& Liang, B. C. (1998). Carbon distribution and losses: erosion and deposition effects. Soil \& Tillage Research, 47, 291-302.

Hancock, G. R., Murphy, D., \& Evans, K. G. (2010). Hillslope and catchment scale soil organic carbon concentration: an assessment of the role of geomorphology and soil erosion in an undisturbed environment. Geoderma, 155, 36-45.

Hirmas, D. R., Amrhein, C., \& Graham, R. C. (2010). Spatial and process-based modeling of soil inorganic carbon storage in an arid piedmont. Geoderma, 154, 486- 494.

Janzen, H. H. (2004). Carbon cycling in earth systems - a soil science perspective. Agriculture, Ecosystems and Environment, 104, 399-417.

Kamoni, P. T., Gicheru, P. T., \& Wokabi, S. M. (2007). Predicted soil organic carbon stocks and changes in Kenya between 1990 and 2030. Agriculture, Ecosystems and Environment, 122, 105-113.

Kemanian, A. R., Julich, S., Manoranjan, V. S., \& Arnold, J. R. (2011). Integrating soil carbon cycling with that of nitrogen and phosphorus in the watershed model SWAT: theory and model testing. Ecological Modelling, 222, 1913-1921.

Lal, R. (2002). Soil carbon dynamics in cropland and rangeland. Environmental Pollution, 116, 353-362.

McCarty, G. W., \& Ritchie, J. C. (2002). Impact of soil movement on carbon sequestration in agricultural ecosystems. Environmental Pollution, 116, 423-430. 
Ozcan, A. U., Erpul, G., Basaran, M., \& Erdogan, H. E. (2008). Use of USLE/GIS technology integrated with geostatistics to assess soil erosion risk in different land uses of Indagi Mountain Pass - Cankiri, Turkey. Environmental Geology, 53, 1731-1741.

Page, M., Trustrum, N., Brackley, H., \& Baisden, T. (2004). Erosion-related soil carbon fluxes in a pastoral steepland catchment, New Zealand. Agriculture, Ecosystems and Environment, 103, 561-579.

Rimal, B. K., \& Lal, R. (2009). Soil and carbon losses from five different land management areas under simulated rainfall. Soil \& Tillage Research, 106, 62-70.

Sanderman, J., \& Amundson, R. (2009). A comparative study of dissolved organic carbon transport and stabilization in California forest and grassland soils. Biogeochemistry, 92, 41-59.

Schwanghart, W., \& Jarmer, T. (2011). Linking spatial patterns of soil organic carbon to topography - a case study from southeastern Spain. Geomorphology, 126, 252-263.

Shi, X. Z., Wang, H. J., Yu, D. S., Weindorf, D. C., Cheng, X. F., Pan, X. Z., Sun, W. X., \& Chen, J. M. (2009). Potential for soil carbon sequestration of eroded areas in subtropical China. Soil \& Tillage Research, 105, 322-327.

Shibu, M. E., Van Keulen, H., Leffelaar, P. A., \& Aggarwal, P. K. (2010). Soil carbon balance of rice-based cropping systems of the Indo-Gangetic Plains. Geoderma, 160, 143-154.

Sitaula, B. K., Bajracharya, R. M., Singh, B. R., \& Solberg, B. (2004). Factors affecting organic carbon dynamics in soils of Nepal/Himalayan region - a review and analysis. Nutrient Cycling in Agroecosystems, 70, 215-229.

Smith, S. V., Bullock, S. H., Hinojosa-Corona, A., Franco-Vizcai, E., Escoto-Rodri, M., Kretzschmar, T. G., Farfa, L. M., \& Salazar-Cesen, J. M. (2007). Soil erosion and significance for carbon fluxes in a mountainous Mediterranean-climate watershed. Ecological Applications, 17, 1379-1387.

Stavi, I., \& Lal, R. (2011). Loss of soil resources from watereroded versus uneroded cropland sites under simulated rainfall. Soil Use and Management, 27, 69-76.

Van Miegroet, H., Boettinger, J. L., Baker, M. A., Nielsen, J., Evans, D., \& Stum, A. (2005). Soil carbon distribution and quality in a montane rangeland-forest mosaic in northern Utah. Forest Ecology and Management, 220, 284-299.

Wang, Z. G., Govers, G., Steegen, A., Clymans, W., Van den Putte, A., Langhans, C., Merckx, R., \& Oost, K. V. (2010). Catchment-scale carbon redistribution and delivery by water erosion in an intensively cultivated area. Geomorphology, 124, 65-74.

Wang, Z., Liu, G. B., Xiu, M. X., Zhang, J., Wang, Y., \& Tang, L. (2012). Temporal and spatial variations in soil organic carbon sequestration following revegetation in the hilly Loess Plateau, China. Catena, 99, 26-33.

Wang, Z. P., Han, X. G., Chang, S. C., Wang, B., Yu, Q., Hou, L. Y., \& Li, L. H. (2013). Soil organic and inorganic carbon contents under various land uses. Catena, 109, 110-117.

Xu, W. Q., Chen, C., Luo, G. P., \& Lin, Q. (2011). Using the CENTURY model to assess the impact of land reclamation and management practices in oasis agriculture on the dynamics of soil organic carbon in the arid region of North-western China. Ecological Complexity, 8, 30-37.

Zhang, X., Li, Z. W., Tang, Z. H., Zeng, G. M., Huang, J. Q., Guo, W., Chen, X. L., \& Hirsh, A. (2013). Effects of water erosion on the redistribution of soil organic carbon in the hilly red soil region of southern China. Geomorphology, 197, 137-144.

Zheng, S. Z., \& Li, X. L. (2009). Study on water resources and its sustainable use in the Haihe River Basin. South-to-North Water Transfers and Water Science \& Technology, 7, 45-47. 